\title{
SEFT Based Individual Counseling to Reduce the Academic Anxiety
}

\author{
Isti Yuni Purwanti and Isniatun Munawaroh \\ Yogyakarta State University
}

\section{Abstract}

The results showed that the level of academic anxiety experienced by junior high school students in the Province of Special District of Yogyakarta can be categorized as moderate. It was also revealed that Guidance and Counseling teachers also have been doing something in reducing these problems by providing counseling either individually or in groups to their students and using a variety of appropriate approaches and techniques, though it was not maximized. Based on these results, the need for more simple and techniques can then be applied when the Guidance and Counseling teachers provide individual counseling services. One technique which can be given is the SEFT technique (Spiritual Emotional Freedom Technique). Due to the problems

Corresponding Author: Isti Yuni Purwanti

istiyp@uny.ac.id

Received: 2 May 2019

Accepted: 19 June 2019

Published: 3 July 2019

Publishing services provided by Knowledge E

(c) Isti Yuni Purwanti and Isniatun Munawaroh. This article is distributed under the terms of the Creative Commons

Attribution License, which permits unrestricted use and redistribution provided that the original author and source are credited.

Selection and Peer-review under the responsibility of the ICMEd Conference Committee.

\section{G OPEN ACCESS} above, this research aims to produce SEFT-based individual counseling skills model in reducing the student's academic anxiety.

Keywords: counseling; SEFT; academic anxiety

\section{Introduction}

Academic anxiety appears in individuals who experience barriers to their academic. Based on research conducted by Isti and Isni (2017), it was revealed that the level of academic anxiety experienced by junior high school students in the Province of Special District of Yogyakarta is in low and medium categories. Academic anxiety raised among others, related to preparing for the exam, for example, the students feel anxiety, fear, stress due to assume that the test was like "scary" thing.

In fact, academic anxiety does not only appear during the exam period, but it may also appear in the daily life of students at the school. For example, anxiousness because they can not do the task (homework), the fear of failure that they can not continue their study to higher education level, concerned with specific subjects, and others. So the fear experienced by the students needs a further intervention of the guidance and counseling teacher in the schools.

Many treatments can be given by guiding and counseling teachers at the school, one of them is individual counseling. The process of individual counseling can be provided 
by using the media. One media which likely to be used is the module. The purpose of the module is so that the guiding and counseling teachers can provide more targeted services and the desired goals can be achieved. Moreover, the module can also be studied by the teachers and directly applicable.

The model which has been generated in this study is a SEFT-based individual counseling skills model to reduce academic anxiety experienced junior high school students. SEFT stands for Spiritual Emotional Freedom Technique, it means that in its process the students are more likely to or directed at their spiritual emotions.

SEFT therapy can be given to individuals who are experiencing problems in their everyday lives and it has been proven to help individuals address their problem. Based on this fact, it is very important if students who experience academic anxiety supplied with individual counseling services which are based on SEFT.

\section{Literature Review}

\subsection{Academic anxiety}

According to Semiun $(2006,356)$ anxiety is a fear response classically conditioned and anxiety disorders which occur as well when the fearful response associated with a stimulus that should not cause fear. The description proves that the stimulus or object that is either still in the mind as well as in the real form does not inspire fear.

Meanwhile, according to Ottens (1991.1) academic anxiety refers to the disruption of thinking patterns and physical responses and the concerns about performed possible behavioral on academic tasks given is very poorly. It is clear that the condition of students when dealing with school exam shows different behaviors or thoughts. For example, they are afraid that they can not do the test, cannot join favorite schools, feel excited (palpitations) before having the exam, even worse a cold sweat.

From the description above it can be concluded that academic anxiety is the thoughts and feelings encouragement of the learners/students that in the form of a fear of the dangers that would come without special cause which results in disturbed mindset, physical responses, and behavior. In other words, it can be said that anxiety is an individual response to the uncertain object. Since, the object is related to the academic field, so it is called an academic anxiety.

Anxiety experienced by students, among others, anxious towards national exams, daily tests, dealing with midterm examination and final examination, and many more. 
The stimulus or the object should not cause excessive fear that eventually can bring anxiety.

\subsection{SEFT-based individual counseling}

According to Willis $(2004,18)$ counseling is relief efforts given by counselor to individuals (counselee) so the counselee to may develop their potential optimally and able to cope with the problem and being able to adapt to the surrounding environment.

The opinion explains that the counseling service is provided by professional experts who are counselors. In a school environment, it is given by guidance and counseling teacher. The purpose of their counseling services to help students coping with the problem and eventually can develop themselves properly and optimally.

One of the approaches or therapy which can be used to overcome the academic anxiety is by SEFT therapy. This therapy was first introduced by Faiz Ahmad Z., and used to address the various problems faced by individuals. For example, phobia with a variety of objects, smoking, insomnia and many more.

SEFT therapy is based on 15 therapeutic techniques, NLP, Sensitized Systematic, Psychoanalysis, Logo therapy, EMDR, Sedona Method, Eriksonian Hypnosis, Provocative Therapy, Suggestion and Affirmation, Creative Visualization, Relaxation \& Meditation, Gestalt Therapy, Energy Psychology, Powerful Prayer, and Loving Kindness Therapy (Zainuddin, 2013).

The process of implementation will also follow the procedures in the SEFT therapy. In terms of the implementation of counseling is the application or the use of this therapy is given when the core stage of the counseling process. The process cannot be separated from the counseling skills which have been mastered by a counselor.

Based on these descriptions, it is appropriate if the academic anxiety experienced by students can be handled by SEFT-based individual counseling. The guidance and counseling teachers who provide such services still also raises the existing counseling skills.

\section{Material \& Methodology}

\subsection{Types of research}

This research was conducted by the Research and Development approach, that is a series of research activities which is then followed up by the development of a product 
in the form of SEFT-based individual counseling models to reduce anxiety academic of junior high school students in the Province of Special District of Yogyakarta.

\subsection{Research design}

The designs in this study refer to the development of research models by Borg and Gall. Broadly speaking, the design needs to conduct need assessment (preliminary studies), planning which is conducted by invitting the guidance and counseling teachers and student representatives from each 5 districts in the province through FGD (Focus Group Discussion). The following step is to try to make the product design, the SEFT-based individual counseling model to reduce anxiety academic of junior high school students.

\subsection{Research subjects}

The subjects in this study were guidance and counseling teachers and junior high school students in the province. These subjects were obtained from the recommendation of Deliberation Teacher of Guidance and Counseling) in each district.

Based on the recommendation above, there were 5 guidance and counseling teachers and 5 students in each district. Since there are five districts in the province (Bantul, Kulon Progo, Gunung Kidul, Sleman and Yogyakarta), the number of teachers and students who became the subjects of the research are 25 teachers and 25 students.

\subsection{Data collection technique}

The data were collected by using several instruments. The instruments are the inventory of academic anxiety and academic anxiety interview guidelines. The inventory of academic anxiety was used to reveal the level of academic anxiety experienced by junior high school students, while the guidance interviews to uncover the guidance and counseling teachers' efforts in dealing with students' academic anxiety.

\subsection{Data analysis technique}

The data analysis used is descriptive quantitative and qualitative since it is based on the research objectives, that is to generate SEFT-based individual counseling model based academic in reducing academic anxiety. 


\section{Results and Discussion}

\subsection{Result}

\subsubsection{Identification of academic anxiety}

Based on the results of academic anxiety inventory, that the grade IX students of junior high school the Province of Special District of Yogyakarta were suspected experiencing academic anxiety in mild and moderate levels, the scores obtained are $\leq 7$. It is also confirmed by the data of FGD with the guidance and counseling teachers of junior high school, that students of grade IX feel anxious when they will face the test in terms of passing the test or even failed, they also worry about whether they can be accepted in the favorite schools or not, pessimistic, they often meet the teachers to ask about the subject matters, they feel they are not yet ready for the exam, they also often play and sweaty as well.

Based on the score of the categorization of a students' academic anxiety inventory, it is classified on the categorization of mild and moderate, then it becomes a benchmark in providing SEFT-based counseling. In SEFT technique there will be tapping given on 18 points of the body. Since the academic anxiety level is categorized as moderate based on the instruments given to the grade IX students of junior high school in this province, then the SEFT technique with 9 points was given during the implementation of individual counseling.

\subsubsection{Teachers' efforts which have been done in addressing the aca- demic anxiety}

Based on the Focus Group Discussion and the guidance and counseling teachers of junior high schools in the Province of Special District of Yogyakarta, it was found that the efforts which have been conducted related to academic anxiety were approaching to students with such anxiety to find out the causes, counseling either individually or in groups, performing those things with various techniques during the counseling. From these results, some teachers have not provided the service by using special techniques and the media.

Therefore, in this study, the researchers try to arrange the use of the media in providing counselling services, especially individual counseling. This model uses the SEFT technique in individual counseling to reduce academic anxiety. 


\subsubsection{SEFT-based individual counseling model to reduce academic anxi- ety of junior high school students in the Province of Special District of Yogyakarta}

The product which has been made is a guidebook which contains SEFT-based individual counseling model to reduce academic anxiety for junior high school students in the Province of Special District of Yogyakarta. The book then has been tested by experts, the media expert and material expert with a score of 85 , which means it is very good and deserves to be tested.

As it has been explained previously that the level of academic anxiety of junior high school students the Province of Special District of Yogyakarta is in the category of low and medium, then SEFT was performed by using 9 points, they are the head, the tip of the eyebrow, the base of the eyebrows, under the eyes, under the nose, chin, sidelines of collarbone, under the armpits and under the breasts. The tapping was done alternately, it started from the right part of the body and then to the left ones. In performing the tapping, it takes two fingers, namely the index finger and middle finger with the tapping which was adjusted to the condition of the counselees or students' body.

Photo illustrations of that show which illustrate some of the skills of individual counseling that should be there, such as attending and empathy are available in this book. These skills can be illustrated with a photograph while other skills are given examples by using the texts. Besides, The stages in performing SEFT techniques and the points of the body which need to tap are also included in this book.

\subsection{Discussion}

Based on these findings, it can be stated that the SEFT based individual counseling skill can reduce academic anxiety. It is not only teachers who are trained and then to apply it in helping the students but the students themselves can do so by using the guidebook which has been created. This technique can be done by themselves after the first treatment is given by counselors primarily for what is associated with academic anxiety of the junior high school students.

In accordance of the opinion of Huberty (2012, Dobson, 2012: 4), that the academic anxiety is common in students and can lead to serious things to deal with, especially if the students' academic achievement is decline. The explanation indicates that academic anxiety does need to be handled by counselors by giving individual counseling services. 
During these times individual counseling services have been conducted by guidance and counseling teachers and counselors by applying the existed approach. Meanwhile, SEFT technique has never been applied because it is a new thing for the teachers and there are only a few counselors who can apply it. The counselors and the experts of SEFT can apply these techniques must attend SEFT training for 2 days and proved to obtain a certificate from its founder.

Basically, SEFT technique is based on the 15 grand theory therein. So, the implementation can be easily used and effective to overcome the barriers or problems being faced by the individuals. In this study, the use of SEFT technique in individual counseling service is to reduce the academic anxiety of junior high school students.

According to Dobson $(2012,7)$, both parents and teachers in schools should recognize or identify the symptoms of academic anxiety experienced by the students. That is the reason why it is important to recognize or identify emerging academic anxiety because it will greatly affect the provision of counseling services.

Based on this fact, it can be said that one of the objectives of the research is to identify students' academic anxiety has been accomplished since the students' academic anxiety can be identified in which category from this identification process. So, it will be clearer in defining the SEFT technique whether using 18 points or 9 points in its application.

The results showed that the level of academic anxiety of the junior high school students is at a low and medium category, it means that it needs 9 points of the SEFT techniques. These 9 points are then underlying the modeling of SEFT-based individual counseling skills in reducing academic anxiety of the junior high school students.

\section{Conclusion}

5.1. The academic anxiety level of Grade IX of junior high school students in the Province of Special District of Yogyakarta is at a low and medium category. It is based on the results of academic anxiety inventory score, that is $\leq 7$. It also supported by the results of Focus Group Discussions and the guidance and counseling teachers of the junior high schools in the province.

5.2. The efforts which have been made of teachers on students who experience academic anxiety is being close to the student to determine the cause, performing both individual and group counseling. The teachers had never known about SEFT techniques before. 
5.3. Based on these data, the SEFT-based individual counseling model guidebooks had been designed to reduce academic anxiety of the junior high school students in the Province of Special District of Yogyakarta

\section{Acknowledgment}

This research is fully supported by Affiliation DPRM Kemenristekdikti (Applied Research Scheme).

\section{References}

[1] Borg, WR \& Gall, MD, 1983. Educational Research, An Introduction. Fourth Edition. New York: Longman.

[2] Dobson, C. 2012. Academic Anxiety and Coping with Anxiety. Northern, Michigan University

[3] Mahato, B. \& Jangir, S. 2012. A Study on the Academic Anxiety among Adolescents of Minicacy Island. International Journal of Science and Research (IJSR), India Online. Volume 1 Issue 3.

[4] Mardapi, D, and Kartowagiran, B., 2009. The impact of the national exam. The research report. Yogyakarta: Graduate University of Yogyakarta.

[5] Semiun, Y., OFM. Mental Health 2006. 2. Yogyakarta: Canisius.

[6] Sugiyono, 2008. Education Research Methods. Bandung: Alfabeta.

[7] Willis, Sofyan, S. 2004. Individual Counseling, Theory and Practice. Bandung: Alfabeta.

[8] Zainuddin Ahmad, F. 2013. SEFTer Handbook. The second edition.

[9] Willis, Sofyan, S. 2014. Individual Counseling, Theory and Practice. Bandung: Alfabeta.

[10] Ottens, AJ (1991). Coping with Academic Anxiety. New York: The Rosen Publishing Group. 